\title{
Creating a project-based degree at a new university in Africa
}

\section{Laurel Staab}

Global Challenges, African Leadership University, Rwanda.

\begin{abstract}
African Leadership University (ALU), a network of higher education institutions, opened its second campus in Rwanda in September of 2017. In order to achieve the institutional vision to educate three million young African Leaders before 2050, the University has made efforts to embrace innovative pedagogy,' designing curricula and training its teaching staff in active learning and student-centered pedagogy. This paper provides an account of the design and inital delivery of a new degree that ALU offers to its students in Rwanda, called "Global Challenges," a project-based degree that requires students to structure their learning around a project that they self-design that addresses a challenge facing the continent of Africa. The paper is authored by a member of the faculty of the new degree and uses qualitative practitionerbased research to describe the degree and analyse its alignment with the innovative practice of Project-Based Learning (PBL). Analysis of the degree design shows strong adherence to the principles of $P B L$; however, more research is needed to evaluate the effectiveness and broader impact of this new educational program.
\end{abstract}

Keywords: Project-Based Learning; Self-directed Learning; Innovative Higher Education; Curriculum Design; Tertiary Education in Africa; Teacher-Based Research. 


\section{Introduction}

Higher education has faced several critical challenges in recent years. An undergraduate degree no longer guarantees employment upon completion (Hersh \& Merrow, 2015). On the continent of Africa, the concern of the ability of graduates to secure employment is particularly pressing, with high levels of unemployment and underemployment among graduates (Bassey \& Atan, 2012). Therefore, many universities have revisited curricula and pedagogy to better equip graduates for the needs of the current and future job markets in order to address a perceived gap between the skills that students receive and the needs of employers (Pauw et al., 2008; Ponge, 2013). Scholars have also pointed to the legacies of colonial education systems across the continent of Africa that stifled critical thinking amongst students, and call for higher education to decolonize both curricula and pedagogical strategies so that African students are equipped with the knowledge and skills to solve problems relevant to their own contexts (Nyamnjoh, 2012). It is important that higher education institutions who are united in their goal to respond to these critical needs of students and their broader societies commit to sharing their innovative strategies that they are implementing to address these challenges.

African Leadership University (ALU) opened its first campus in Mauritius in 2015 and its second campus in Rwanda in September of 2017 (Gwaambuka, 2016). The institutional mission is to develop leaders for the African continent, and its existence is a direct response to issues of graduate unemployment and the skills gap on the continent, with its emphasis on 21 st-century skills, career development, and entrepreneurial thinking (ALU, 2020). ALU has made innovative pedagogy a critical part of the method that it uses to develop and create leaders, with the rationale that this will equip students with the knowledge and skills needed to not only find employment, but also become leaders who will address important challenges facing the continent of Africa. ${ }^{1}$ In order to achieve this, ALU has created its own unique curricula and trains its teaching staff to use student-centered pedagogical strategies (Baker, 2019). A key example of this innovative pedagogy is the Global Challenges degree that is accredited and offered at the ALU Rwanda campus. It is designed as a project-based degree in which students 'declare a mission' and design their own project that works to solve or address a challenge that is facing the continent of Africa, providing students with an innovative learning experience that equips them to solve problems related to their own contexts and communities (Faraj, 2019).

\footnotetext{
1 While there are many contested definitions for what constitutes "innovative pedagogy," (and innovation more broadly), for the purpose of this paper I will use the term to indicate instructional methods and curricula that (1) incorporate recent research in how people learn and (2) provide students with knowledge and skills that equip them to be responsive to the dynamic current and future needs of their society.
} 
As a faculty member who participated in both the design and subsequent delivery of the Global Challenges degree, my analysis of the Global Challenges degree at ALU explores a primary research question: how does ALU's Global Challenges Degree adhere to the key aspects of Project Based Learning? This paper adds to the body of research that discusses the complexity of implementing quality innovative educational strategies. It offers the unique perspective of implementing these strategies at an institutional level in a newly established higher education institution in Africa, responding to the call for more examples of practitioner based research in education (Campbell, 2013).

\section{Literature Review}

\subsection{Grounding PBL in Learning Theory}

In order to discuss the implementation of a project-based degree, it is important to examine the existing body of research about the practice of PBL and its links to learning theory. PBL has earned its place in the catalogue of innovative educational practices due to its ability to foster inquiry, practical application of knowledge and skills, and create engaging opportunities for students to learn and demonstrate their learning (DeFillippi, 2001; Thomas, 2000). For PBL to be properly implemented, student choice and autonomy should drive an inquiry-based process in which students construct their own meaning through creative processes. This practice is grounded in Seymour Papert's theory of Constructionism, where students learn and create meaning by linking new concepts to prior knowledge and concrete artifacts that they already understand (Ackermann, 2001; Papert, 1980).

\subsection{Implementing $P B L$}

While PBL offers much potential as a pedagogical strategy grounded in progressive educational theory, there is also an important body of research that discusses the challenges of implementing PBL. It requires a system that provides students with autonomy and choice, an assessment strategy that can properly evaluate student learning beyond traditional examinations, and skilled teachers who understand both the purpose of PBL and the best ways to implement it in order to support students in their learning (Barron et al., 1998; Blumenfeld et al., 1991). The Cognition and Technology Group and Vanderbilt identified both important principles that educators should enact to support project-based learning and provide support to students transitioning to $\mathrm{PBL}$, including having "learning-appropriate goals, scaffolds that support both student and teacher learning, frequent opportunities for formative self-assessment and revision, and social organizations that promote participation and result in a sense of agency" (Barron et al., 1998). These changes to traditional systems prove challenging to create and maintain both for institutions, and can present challenges for students who are not accustomed to working with high levels of autonomy and choice. 


\subsection{PBL in Higher Education}

Progressive primary and secondary school teachers have worked to implement PBL in their instruction, but there are fewer examples of higher education embracing this practice where the lecture based model remains prevalent. However, the process of inquiry-based research conducted at higher education institutions is well-suited to align with PBL (Lee et al., 2014). Due to the need for high levels of student autonomy and self-direction needed for PBL, practitioners and researchers have highlighted the effectiveness of implementing PBL in higher education as adult learners are often better equipped to embrace autonomy and flexible structures (De Bruin, 2007; Donnelly \& Fitzmaurice, 2005). Indeed, efforts at implementing constructionist PBL in more technical and STEM related fields has led to promising results (De los Ríos-Carmenado et al., 2015).

\section{Methods and Data}

\subsection{Practitioner Methodology}

As a faculty member of the Global Challenges degree who has been involved in both the design and the delivery of the degree, using a qualitative practitioner method of inquiry is called for in order to investigate questions directly pertaining to my work (Anderson et al., 2007; Creswell, 2002). In line with participatory research and action research, the findings of this research can be applied to my practice in order to improve my students' learning and overall experience of the degree (Anderson et al., 2007; Foreman-Peck, 2010).

\subsection{Description of Data}

Data used for this paper includes curriculum design documentation and initial documents created by staff of ALU and program and module retrospective documentation created by faculty of the degree at the end of each term. Data was purposefully selected as an extreme case sample due to the unique nature of a newly established degree.

\subsection{Research Limitations}

Due to the subjective nature of the practitioner method of research, any conclusions drawn from the data are preliminary and not to be considered more broadly generalisable outside of the particular program. The results and discussion are meant to share insights related to the implementation of a new PBL degree so that other practitioners can learn from these perspectives; however, they are by no means a full representation of all staff and students perspectives. 


\section{Results}

\subsection{Conception of the Degree}

The initial idea for the Global Challenges degree came from the institution's founder, who worked with 'learning experience designers' to articulate four foundational principles of the degree:

"Students are at the center of the learning experience.

Each student's individual passion is the starting point for their journey at ALU. With the goal of the impact they hope to make on the world in mind, students pursue personalized learning experiences to enable them to maximize their potential and achieve their intended impact.

Global Challenges gives direction, meaning, and purpose to our pursuits

One's chosen challenge, and the individual mission that they set out to accomplish within it, guide students to devote our talents to shaping a better world. It is often bemoaned that the greatest minds of the current generation are devoted to figuring out how to compel someone to click on online advertisements (Google, Facebook, etc). By framing students' education around the seven grand challenges facing the world, we will ensure the greatest minds of the next generation are devoted to solving the world's greatest problems.

\section{Missions are aimed at authentic, relevant, and comprehensible problems}

Students declare a 'mission' for their life to solve a specific problem within one of the grand challenges. These problems should be authentic, relevant, and comprehensible. By "authentic" we mean problems that have scientific evidence demonstrating their existence, by "relevant" we mean the problem has importance to the world beyond academia, and by "comprehensible" we mean that it can be studied, analyzed and potentially solved using the tools of science and entrepreneurship.

Projects connect us to the real world, grounding and focusing our work

In order to ensure that students are connected to the leading work happening in each global challenge, students will regularly pursue real projects with partner organizations. These opportunities for application of knowledge will make the learning more enduring while keeping them firmly planted in daily realities of the field" (ALU, 2018).

ALU identified 'Seven Grand Challenges' facing the continent of Africa and the broader world that students may choose to focus their studies around. They are Education, Urbanization, Healthcare, Climate Change, Governance, Job Creation, and Infrastructure. ALU subsequently expanded the list to include 'Seven Great Opportunities' that exist on the continent of Africa, which are Agriculture, Natural Resource Management, Wildlife 
Conservation, Regional Integration, Arts, Design, and Culture, Tourism, and Empowerment of Women.

\subsection{Description of the Degree}

The degree centers around students reflecting on their passions and interests, declaring a 'mission' related to one or more of the Grand Challenges and Opportunities, and designing their own project that works to address a problem related to their mission, culminating in a final capstone project. Students take two series of modules to equip them with the skills necessary to create their project. The first is a series of research methods classes where they learn qualitative, quantitative, and mixed methods that allows them to conduct in depth research related to their missions and projects. The second is the 'mission' series, in which students identify their mission, use human-centered design to articulate a problem and refine a potential solution, and create a project that puts their solution into action. Students also choose from a series of electives related to their missions and the 'Seven Grand Challenges and Seven Great Opportunities' in order to gain greater understanding of the contexts of their missions and projects.

\section{Discussion and Conclusion}

The initial conception of the degree is strongly aligned with the theory and practice of PBL. ALU's emphasis on student-centered agency through their ability to choose and design their own mission and related project is key to the degree's adherence to the PBL methodology (Barron et al., 1998; Thomas, 2000). Additionally, the creation of a menu of 'Grand Challenges and Opportunities' provides students with scaffolded supported choices with which to shape their projects, while providing them the opportunity to explore topics that are practical and relevant to their own contexts (Barron et al., 1998). While the original vision for the degree did not require that students take traditional modules, regulatory requirements necessitated a more traditional module structure which led to the design of the key 'streams' of research modules and mission modules.

There are, however, key challenges that have emerged in the implementation of the degree. One challenge is the transition that students face from a more traditional education system that is highly structured to one with high levels of autonomy and responsibility. For many students, this can be overwhelming, and while some students thrive with this level of autonomy, others struggle to manage their time and work. Another is a concern that both faculty and students express regarding depth of study. Because students are encouraged to choose unique projects that they are passionate about, they often find themselves researching topics outside of any area of expertise of the existing faculty. In theory students become highly skilled at research so that they can pursue their own depth of knowledge; however, in 
practice, this can be quite challenging for undergraduate students pursuing new fields that they have little frame of reference for.

Additionally, this degree is in very early stages of implementation, and the first cohort has yet to graduate. More research is needed to draw any conclusions about the effectiveness of this degree on student achievement, life outcomes, and the broader impact that graduates have on society.

\section{References}

Ackermann, E. (2001). Piaget's constructivism, Papert's constructionism: What's the difference. Future of Learning Group Publication, 5(3), 438.

ALU. (2018). African Leadership University Blueprint for Transformative Education. ALU Internal Document.

ALU. (2020). The ALU Advantage. ALU. https://www.alueducation.com/alu-advantage/

Anderson, G. L., Herr, K., \& Nihlen, A. S. (2007). Studying your own school: An educator's guide to practitioner action research. Corwin Press.

Baker, A. (2019, June 11). The African Leadership University Hopes to End Brain Drain | Time. https://time.com/5603886/african-leadership-university-mauritius-fred-swaniker/

Barron, B. J., Schwartz, D. L., Vye, N. J., Moore, A., Petrosino, A., Zech, L., \& Bransford, J. D. (1998). Doing with understanding: Lessons from research on problem-and projectbased learning. Journal of the Learning Sciences, 7(3-4), 271-311.

Bassey, G. E., \& Atan, J. A. (2012). Labour Market Distortions and University Graduate Unemployment in Nigeria: Issues and Remedies.

Blumenfeld, P. C., Soloway, E., Marx, R. W., Krajcik, J. S., Guzdial, M., \& Palincsar, A. (1991). Motivating Project-Based Learning: Sustaining the Doing, Supporting the Learning. Educational Psychologist, 26(3-4), 369-398. https://doi.org/10.1080/00461520.1991.9653139

Campbell, K. H. (2013). A Call to Action: Why We Need More Practitioner Research. $20,8$.

Creswell, J. W. (2002). Educational research: Planning, conducting, and evaluating quantitative. Prentice Hall Upper Saddle River, NJ.

De Bruin, K. (2007, January 1). The relationship between personality traits and self-directed learning readiness in higher education students. https://www.ingentaconnect.com/content/sabinet/high/2007/00000021/00000002/art000 04

De los Ríos-Carmenado, I., Lopez, F. R., \& Garcia, C. P. (2015). Promoting professional project management skills in engineering higher education: Project-based learning (PBL) strategy. International Journal of Engineering Education, 31(1), 184-198.

DeFillippi, R. J. (2001). Introduction: Project-based learning, reflective practices and learning. Sage Publications Sage CA: Thousand Oaks, CA. 
Donnelly, R., \& Fitzmaurice, M. (2005). Collaborative project-based learning and problembased learning in higher education: A consideration of tutor and student role in learnerfocused strategies.

Faraj, G. (2019, April 23). Moonshot Thinking for Global Challenges. Medium. https://medium.com/the-alu-editorial/moonshot-thinking-for-global-challengese45184710dbf

Foreman-Peck, L. (2010). Using Educational Research to Inform Practice: A Practical Guide to Practitioner Research in Universities and Colleges (1st ed.). Routledge. https://doi.org/10.4324/9780203847619

Gwaambuka, T. (2016, December 20). The Ground-breaking African Leadership University is Coming to Rwanda | The African Exponent. The African Exponent. https://www.africanexponent.com/post/8167-the-ground-breaking-african-leadershipuniversity-is-coming-to-rwanda

Hersh, R. H., \& Merrow, J. (2015). Declining by Degrees: Higher Education at Risk. St. Martin's Publishing Group.

Lee, J. S., Blackwell, S., Drake, J., \& Moran, K. A. (2014). Taking a leap of faith: Redefining teaching and learning in higher education through project-based learning. Interdisciplinary Journal of Problem-Based Learning, 8(2), 2.

Nyamnjoh, F. B. (2012). 'Potted Plants in Greenhouses': A Critical Reflection on the Resilience of Colonial Education in Africa. Journal of Asian and African Studies, 47(2), 129-154. https://doi.org/10.1177/0021909611417240

Papert, S. (1980). Mindstorms: Computers, children, and powerful ideas. NY: Basic Books.

Pauw, K., Oosthuizen, M., \& Westhuizen, C. V. D. (2008). Graduate Unemployment in the Face of Skills Shortages: A Labour Market Paradox1. South African Journal of Economics, 76(1), 45-57. https://doi.org/10.1111/j.1813-6982.2008.00152.x

Ponge, A. (2013). Graduate Unemployment and Unemployability in Kenya: Transforming University Education to Cope with Market Demands and the Lessons for Africa. 2(3), 12.

Thomas, J. W. (2000). A review of research on project-based learning. 46. 